\title{
Erratum to: Andronov-Hopf bifurcation and sensitivity analysis of a time-delay HIV model with logistic growth and antiretroviral treatment
}

Rachadawan Darlai ${ }^{1{ }^{*}+}$ and Elvin J Moore ${ }^{2,3+}$

\section{"Correspondence:}

rachadawan.d@sciee.kmutnb.ac.th

'Faculty of Science, Energy and

Environment, King Mongkuts

University of Technology North

Bangkok (Rayong Campus), Rayong,

Thailand

Full list of author information is

available at the end of the article

${ }^{\dagger}$ Equal contributors

\section{Erratum}

In the publication of this article [1], there was an error that the Acknowledgments section was missing. It instead should indicate 'This research is supported by the Centre of Excellence in Mathematics, the Commission on Higher Education, Thailand'

This has now been included in this erratum.

${ }^{1}$ Faculty of Science, Energy and Environment, King Mongkuts University of Technology North Bangkok (Rayong Campus), Rayong, Thailand. '2Department of Mathematics, King Mongkuts University of Technology North Bangkok, Bangkok,

Thailand. ${ }^{3}$ Centre of Excellence in Mathematics, CHE, Si Ayutthaya Road, Bangkok, 10400, Thailand.

\section{Publisher's Note}

Springer Nature remains neutral with regard to jurisdictional claims in published maps and institutional affiliations.

Received: 7 July 2017 Accepted: 7 July 2017 Published online: 01 September 2017

\section{References}

1. Darlai, R, Moore, EJ: Andronov-Hopf bifurcation and sensitivity analysis of a time-delay HIV model with logistic growth and antiretroviral treatment. Adv. Differ. Equ. 2017, Article ID 138 (2017). doi:10.1186/s13662-017-1195-1 